Original Article

Artigo Original

Marcela Lima Silagi ${ }^{1}$

Vivian Urbanejo Romero ${ }^{2}$

Leticia Lessa Mansur²

Marcia Radanovic ${ }^{1}$

Keywords

Inferences

Reading

Comprehension

Age Effect

Educational Status

Descritores

Inferências

Leitura

Compreensão

Efeito Idade

Escolaridade
Correspondence address:

Marcela Lima Silagi

Rua Cipotânea, 51, Cidade Universitária, São Paulo (SP), Brasil, CEP: 05360-160.

E-mail: marcelasilagi@usp.br;

marcela_silagi@hotmail.com.br

Received: 12/11/2013

Accepted: 07/22/2014

\section{Inference comprehension during reading: influence of \\ age and education in normal adults}

\section{Compreensão de inferências durante a leitura: influência da idade e escolaridade em adultos normais}

\begin{abstract}
Purpose: To determine the effect of age and education on inferential comprehension from written texts in normal individuals. Methods: A total of 224 normal adults were stratified into nine groups according to age (young: 18-39 years, adults: 40-59 years, and elderly: 60-79 years) and educational level (low $\leq 4$ years, medium: 5-8 years and high $>8$ years) and were evaluated through the battery La gestion de l'implicite (Implicit Information Management Test) to determine the ability to make inferences through different types of questions: explicit, logical, distractor, pragmatic and others. Results: The elderly showed worse performance for total score and distractor questions. Regarding educational level, all groups differed on explicit, logical, distractor questions, and on total test score. Subjects with high schooling performed better on pragmatic inferences and others. Conclusion: Age influence on the comprehension of inferences may be due to difficulties in attention and executive functions. The strong effect of education can be explained by the interaction of inferential abilities with other cognitive functions such as working memory, vocabulary span, as well as world knowledge.
\end{abstract}

\section{RESUMO}

Objetivo: Verificar o efeito da idade e escolaridade na compreensão de inferências a partir de textos escritos em indivíduos normais. Métodos: 224 adultos foram divididos em nove grupos, de acordo com a idade (jovens: 18-39 anos, adultos: 40-59 anos e idosos: 60-79 anos) e escolaridade (baixa $\leq 4$ anos, média: 5-8 anos e alta $>8$ anos) e avaliados por meio da bateria La gestion de l'implicite (Teste de Gerenciamento do Implícito) para determinar a habilidade de compreender inferências, através de diferentes tipos de questões: explícitas, lógicas, distratoras, pragmáticas e outras. Resultados: Os idosos apresentaram pior desempenho na pontuação total do teste e nas questões distratoras. Quanto à escolaridade, todos os grupos se diferenciaram nas questões explícitas, lógicas, distratoras e na pontuação total do teste. Os sujeitos com alta escolaridade apresentaram melhor desempenho nas inferências pragmáticas e outras. Conclusão: A influência da idade na compreensão de inferências pode estar relacionada a dificuldades atencionais e de funções executivas. O forte efeito da escolaridade deve-se à interação da habilidade inferencial com diversas funções cognitivas, como linguagem e memória operacional, além de conhecimento de mundo.

Study carried out at the Department of Neurology, School of Medicine, Universidade de São Paulo - USP São Paulo (SP), Brazil.

(1) Department of Neurology, School of Medicine, Universidade de São Paulo - USP - São Paulo (SP), Brazil. (2) Department of Physiotherapy, Speech-Language and Hearing Sciences and Occupational Therapy, School of Medicine, Universidade de São Paulo - USP - São Paulo (SP), Brazil.

Conflict of interests: nothing to declare. 


\section{INTRODUCTION}

Reading comprehension is one of the most important skills in modern society. Prerequisites for this ability involve a series of competencies, including the capacity to decode stimuli and to retrieve the meaning of words and their syntactic and semantic combinations (phonological, lexical, morphosyntactic and semantic skills) $)^{(1)}$. However, to attain deeper levels of interpretation, the role of world knowledge and the ability to perform more complex mental processes such as inferences are essential ${ }^{(2)}$.

Inferences consist of mental representations constructed by the listener/reader during comprehension of a text, based on the application of their own knowledge together with the information contained in the message, allowing relationships and associations to be formed to enable comprehension of implicit information $^{(3)}$.

Inferential processing is considered a linguistically and cognitively high demanding task that requires several skills, including: linguistic and conceptual knowledge, integrity of attentional processing as well as memory systems (immediate, long-term and working memories), theory of the mind and executive functions, as well as the ability to integrate these skills with prior world knowledge ${ }^{(4,5)}$.

Performance on these linguistic-cognitive tasks related to the inferential processing is highly correlated with sociodemographic factors, and the influence of age and schooling in this tasks is well recognized in the literature ${ }^{(6-8)}$.

Studying the age variable helps elucidate how different linguistic-cognitive functions are processed in the course of normal aging ${ }^{(9)}$. The study of the effect of schooling on the processing of cognitive-linguistic skills has proven fundamental, since the education variable is associated with better performance on cognitive tasks, and has been shown to influence brain organization via structural, volumetric and functional changes, and also to act as a protective factor in the event of neurological disorders ${ }^{(10)}$.

Reading inferential abilities are required in several everyday situations for the correct interpretation of most information presented in written form, in school, professional, recreational, and personal environments. It is also essential in the process of decision-making in which the individual needs to mobilize resources from judgment, reasoning and interpretation of information.

Comprehension of textual inferences is a critical component and a major indicative of a person`s competence in reading skills. However, studies addressing the inferential processes are scarce, given the inherent complexity of such ability, which is intermingled and relies on several other cognitive skills (literacy proficiency, episodic memory, attention, and executive functions, to name a few). There are also few studies about the influence of aging and different levels of schooling in this skill. Therefore, the aim of this study was to determine the effect of age and education on reading comprehension of texts demanding inferences in normal adults in an effort to further explore the influence of these variables in high-complexity language tasks.

\section{METHODS}

\section{Participants}

This study was approved by the Ethics and Research Committee from Hospital das Clínicas of the School of Medicine of Universidade de São Paulo (CAPPesq n. 0813/09). After receiving complete information on the procedures, and as a requisite to enrollment in the study, all participants signed an informed consent.

The study sample comprised 224 healthy adults of both genders, all native Brazilian Portuguese speakers, with no cognitive complaints.

The sample was divided into nine comparable groups according to age: young $(\mathrm{Y})-18$ to 39 years, young adults $(\mathrm{A})$ 40 to 59 years and elderly (E) -60 to 79 years and educational level: low (LE) - less than four years, medium (ME) - five to eight years and high (HE) - greater than eight years. Education was measured by years of formal education in teaching institutions. Age, education and gender characteristics of each group are presented in Table 1.

To be eligible for study enrollment, participants had to meet the inclusion criteria for studies in Neuropsychology described in Mayo Older American Normative Studies (MOANS $)^{(11)}$. These criteria primarily include an absence of cognitive complaints or psychiatric/neurologic disorders, no recent use of psychoactive drugs, and no alcohol dependence. The participants should also present scores consistent with normative values for the Brazilian population on the following tests: Mini-Mental State Examination ${ }^{(12)}$, semantic Verbal Fluency Test (sVF) in the animals category ${ }^{(13)}$, Hamilton Depression Scale - 21-item ${ }^{(14)}$ and the Memory Complaint Questionnaire (Mac-Q) $)^{(15)}$.

Individuals with non-corrected visual deficits or inability to decode and comprehend basic written sentences and paragraphs were excluded. The latter task was verified by a screening test containing questions taken from the Boston Diagnostic Aphasia Examination $^{(16)}$, on which participants had to answer at least $85 \%$ of questions correctly.

\section{Materials and procedure}

Assessment of the ability to comprehend written textual inferences was carried out using the Brazilian Portuguese version of the La gestion de l'implicite (Implicit Information Management Test $)^{(17)}$.

The original instrument in French was previously translated into Portuguese. The translation process of the test followed the recommendations of the International Society for Pharmacoeconomics and Outcomes Research, according to the steps described below:

1. obtaining the author's and publisher's permissions to use the test;

2. translation from French into Portuguese by two professionals with proficiency in both languages, generating two independent versions; 
3. reconciliation held by a third person with knowledge in both languages (consensus), based on the original instrument and the two versions in Portuguese;

4. back translation into French;

5. revision of back translation by two professionals with proficiency in both languages, independently and

6. application of the test in a pilot sample (20 subjects) to verify translation inconsistencies that could interfere in the performance; in this stage, the instrument was considered suitable for the application in Brazilian Portuguese speakers.

The rationale for choosing the test was based on the close linguistic resemblance of the Portuguese and French languages (both Latin languages), particularly with regards to syntactic structure. The instrument is designed for use in adults with neurological impairments such as focal lesions, dementia syndromes and in individuals presenting with cognitive or communication complaints, serving as a diagnostic aid.

The test consists of 20 short texts, which individuals must read and then answer three questions for each by responding with "Yes", "No" or "I cannot answer". The texts comprise a scene involving two speakers or describe a verbal interaction. These narratives constitute affirmative statements, which define a fact or present a problematic situation. The texts contain both explicit and implicit information which are important for correct interpretation during reading. Questions are subdivided into five categories (explicit, logical, distractor, pragmatic and others), which require different types of inferential reasoning. Summarized information and examples are present in Appendix 1.

The evaluation was performed in a silent environment during a single session for each participant. No time limits were imposed and the application procedure was as per the instructions in the original manual, translated into Portuguese.

\section{Data analysis}

The participants' performance was analyzed with regard to total correct answers and scores on the five question categories requiring different inferences. Results were compared taking into account the variables age and educational level.

For the statistical analysis, means, standard deviations and variation of all demographic variables and performance on the textual inference test for all nine subgroups were calculated. Comparison of means for continuous data was performed using one-way ANOVA given the Gaussian distribution of the data. In the case of statistically significant difference among groups, a post hoc (Student's $t$ ) test was applied for pair-wise comparison.

Factorial analysis of variance (two-way ANOVA) was employed to analyze the effect of the factors age and education on making textual inferences. A 5\% level of statistical significance was adopted for all analyses. Analyses were performed using the statistical software program MedCalc ${ }^{\circledR}$ for Windows, version 12.0.3.0.

\section{RESULTS}

There were not age differences among groups when classified by this variable, i.e., among young individuals within the three levels of schooling (YLE x YME x YHE); the same holds true for adults (ALE x AME x AHE), and the elderly (ELE x EME x EHE). There were not differences in educational level among groups when classified by this variable, i.e., among individuals with low education within the three levels of age (YLE x ALE x ELE); the same holds true for medium education (YME x AME $x$ EME), and high education (YHE x AHE x EHE) (Table 1). There were not differences in gender frequency among all groups (Table 1).

Comparison of groups by age revealed that the adult group had better performance than the elderly group on distractor questions and on total test score. There were not differences among age groups on explicit questions, logical and pragmatic inferences, distractors and others score. Regarding educational level, all groups differed on explicit questions, logical inferences, distractors and on total test score, where high educated individuals performed better than low and medium educated ones, and medium educated individuals performed better than low educated ones. In addition, participants with high educational level had better

Table 1. Demographic characteristics of the sample

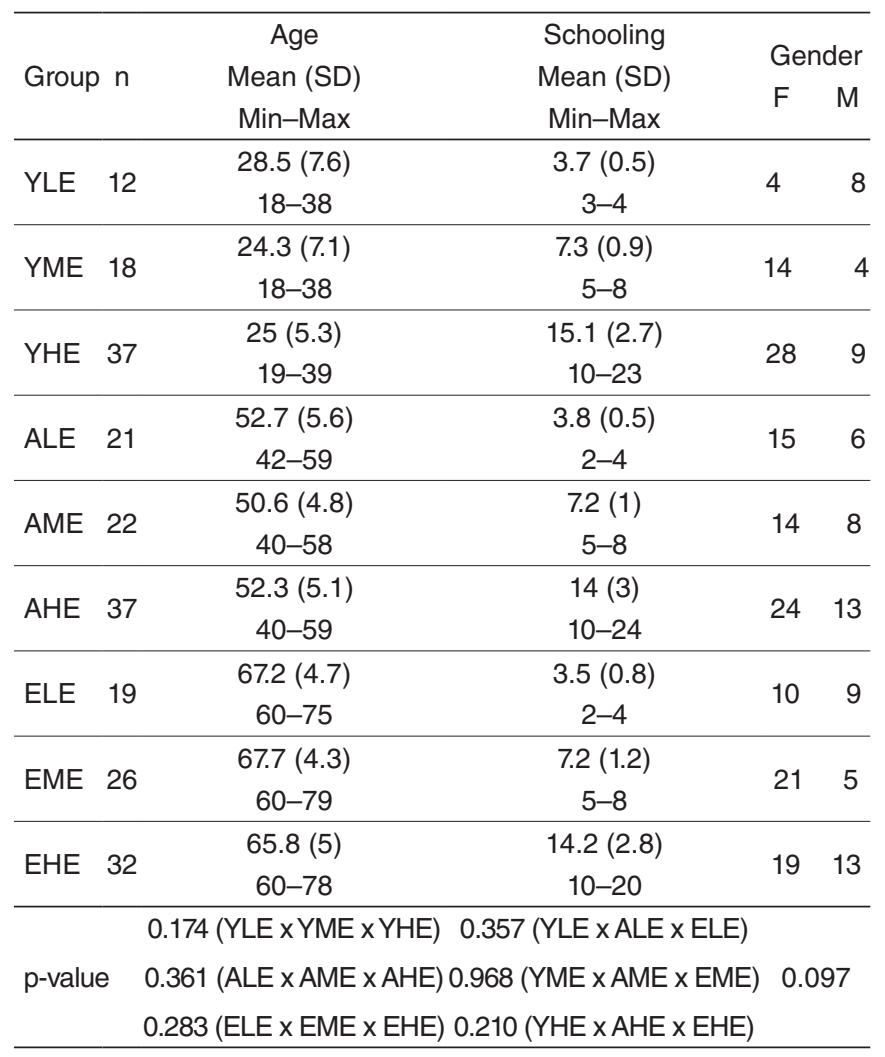

Caption: $\mathrm{SD}=$ Standard Deviation; $\mathrm{Min}=$ Minimum; $\mathrm{Max}=$ Maximum; $\mathrm{F}=$ Female; $\mathrm{M}=$ Male; $\mathrm{YLE}=$ Young, low education; $\mathrm{YME}=$ Young, medium education; $\mathrm{YHE}=$ young, high education; $\mathrm{ALE}=$ Adult, low education; $\mathrm{AME}=$ Adult, medium education; $\mathrm{AHE}=$ Adult, high education; ELE = Elderly, low education; EME = Elderly, medium education; $\mathrm{EHE}=$ Elderly, high education 
Table 2. Performance of groups on textual inference tests by age and educational level

\begin{tabular}{|c|c|c|c|c|c|c|}
\hline \multirow{3}{*}{ Group } & Logical & Explicit & Pragmatic & Distractors & Others & Total \\
\hline & Mean (SD) & Mean (SD) & Mean (SD) & Mean (SD) & Mean (SD) & Mean (SD) \\
\hline & Min-Max & Min-Max & Min-Max & Min-Max & Min-Max & Min-Max \\
\hline \multirow{2}{*}{ YLE } & $6.4(2.1)$ & $8.2(2.1)$ & $12.6(3.1)$ & $4(4.2)$ & $3(0.9)$ & $34.2(7.2)$ \\
\hline & $3-11$ & $3-11$ & $7-17$ & $0-13$ & $1-4$ & $24-48$ \\
\hline \multirow{2}{*}{ YME } & $7.8(2.7)$ & $9.1(2.1)$ & $12.9(2.5)$ & $6.8(4)$ & $3.2(1.4)$ & $40(8.6)$ \\
\hline & $2-12$ & $4-11$ & $8-17$ & $0-13$ & $1-5$ & $25-54$ \\
\hline \multirow{2}{*}{ YHE } & $10.5(1.3)$ & $10.4(0.9)$ & $14.7(1.9)$ & $12.4(1)$ & $4(1)$ & $52(4)$ \\
\hline & $7-12$ & $8-11$ & $8-18$ & $9-13$ & $2-6$ & $44-59$ \\
\hline \multirow{2}{*}{ ALE } & $7.7(1.7)$ & $8.7(1.8)$ & $13.9(2.7)$ & $5.4(4.8)$ & $3.2(1.5)$ & $38.9(7.5)$ \\
\hline & $4-11$ & $5-11$ & $5-17$ & $0-13$ & $1-6$ & $28-53$ \\
\hline \multirow{2}{*}{ AME } & $8.7(1.9)$ & $9.6(1.2)$ & $14.8(2)$ & $8.2(2.6)$ & $3.4(1.2)$ & $44.7(5.1)$ \\
\hline & $5-12$ & $8-11$ & $11-18$ & $3-13$ & $1-6$ & $34-55$ \\
\hline \multirow{2}{*}{$\mathrm{AHE}$} & $9.8(1.5)$ & $10(1.1)$ & $13.9(2.6)$ & $11.1(2)$ & $3.7(1.1)$ & $48.6(5.8)$ \\
\hline & $6-12$ & $6-11$ & $6-18$ & $4-13$ & $1-6$ & $34-60$ \\
\hline \multirow{2}{*}{ ELE } & $6.2(1.6)$ & $8.7(1.7)$ & $13(3.2)$ & $4.3(3.5)$ & $2.8(1)$ & $35.1(7)$ \\
\hline & $3-9$ & $6-11$ & $5-17$ & $0-11$ & $1-4$ & $19-48$ \\
\hline \multirow{2}{*}{ EME } & $7.6(2.1)$ & $9.4(1.8)$ & $14(2.6)$ & $6.7(3.8)$ & $3.4(1.4)$ & $41(8.8)$ \\
\hline & $3-11$ & $4-11$ & $8-18$ & $0-12$ & $1-6$ & $24-53$ \\
\hline \multirow{2}{*}{ EHE } & $9.7(1.7)$ & $10(1.2)$ & $14.5(2.6)$ & $9.6(2.9)$ & $3.6(0.9)$ & $47.5(5.6)$ \\
\hline & $5-12$ & $7-11$ & $10-18$ & $0-13$ & $1-6$ & $32-57$ \\
\hline Age factor ( $p$-value) & 0.050 & 0.799 & 0.204 & $\begin{array}{c}0.030^{*} \\
A \times E(0.025)\end{array}$ & 0.542 & $\begin{array}{c}0.026^{*} \\
A \times E(0.025)\end{array}$ \\
\hline Education factor ( $p$-value) & $\begin{array}{l}<0.001^{*}- \\
\text { all differ }\end{array}$ & $\begin{array}{l}<0.001^{*}- \\
\text { all differ }\end{array}$ & $\begin{array}{c}0.027^{*} \\
\text { LE } \times \text { HE }(0.022)\end{array}$ & $\begin{array}{l}<0.001- \\
\text { all differ }\end{array}$ & $\begin{array}{c}<0.001^{*} \\
\text { LE } \times \mathrm{HE}(<0.001)\end{array}$ & $\begin{array}{l}<0.001^{*}- \\
\text { all differ }\end{array}$ \\
\hline $\begin{array}{l}\text { Interaction age } x \text { education } \\
\text { (p-value) }\end{array}$ & 0.059 & 0.569 & 0.079 & 0.072 & 0.646 & 0.008 \\
\hline
\end{tabular}

Caption: SD = Standard Deviation; Min = Minimum; Max = Maximum; YLE = Young, low education; YME = Young, medium education; YHE = young, high education; $\mathrm{ALE}=$ Adult, low education; $\mathrm{AME}=$ Adult, medium education; $\mathrm{AHE}=$ Adult, high education; ELE = Elderly, low education; EME = Elderly, medium education; EHE = Elderly, high education

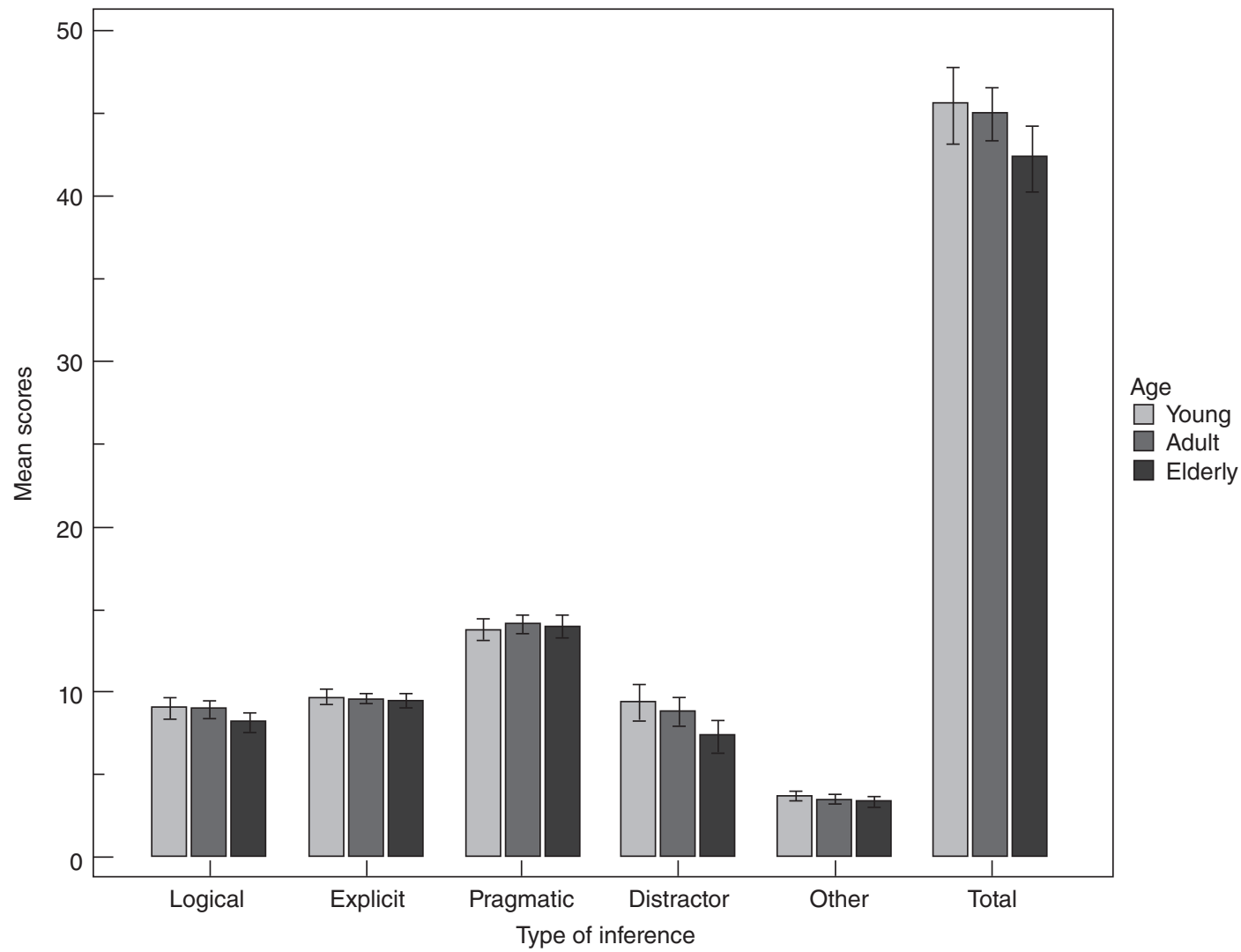

Figure 1. Mean scores obtained by subjects in each type of inference according to age 


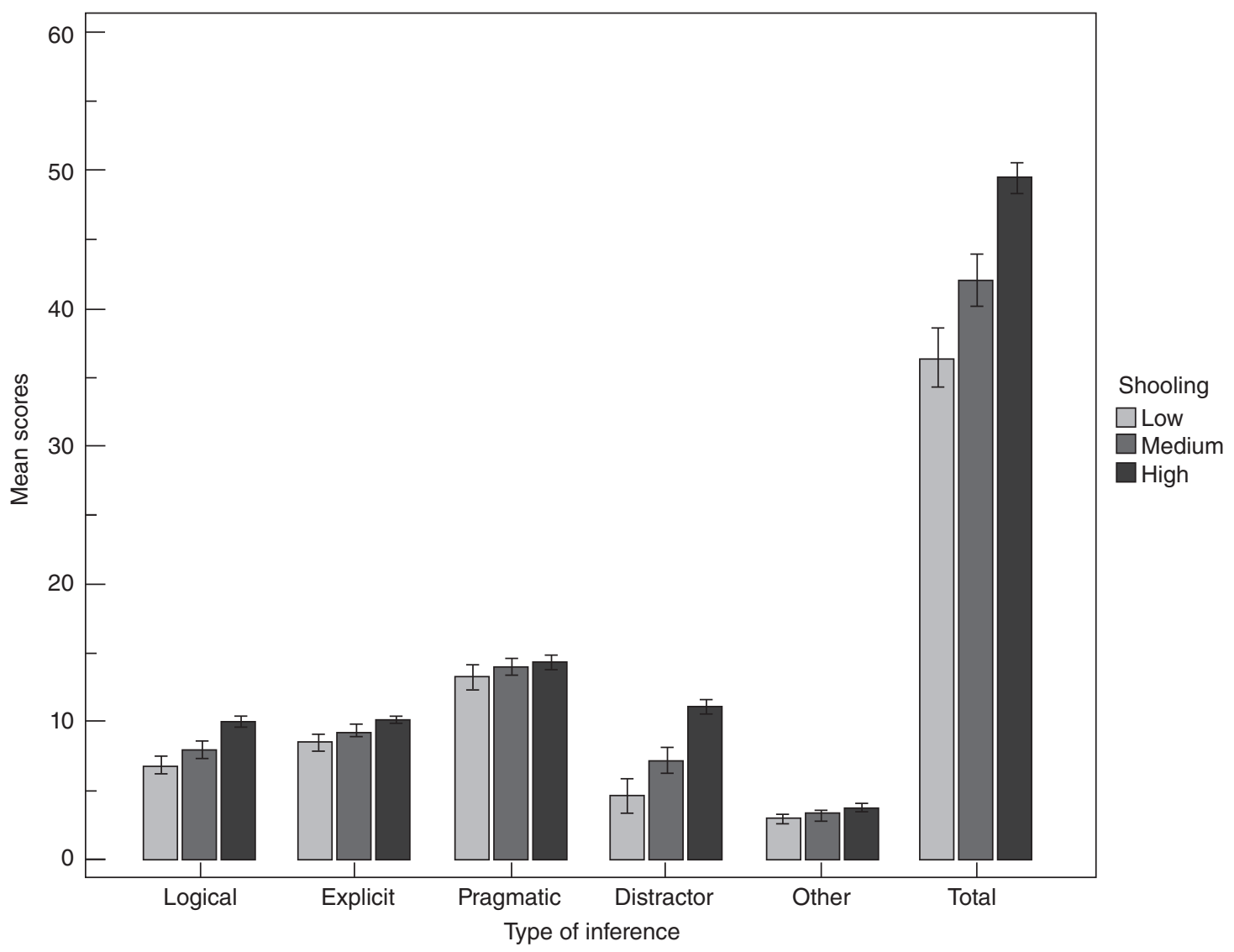

Figure 2. Mean scores obtained by subjects in each type of inference according to schooling

performance on pragmatic inferences and others compared to individuals with low-educational level. An age versus education interaction was observed only on total correct answers (Table 2; Figures 1 and 2).

\section{DISCUSSION}

Developing countries (such as Brazil) provide a vast field for research on the influence of age and schooling variables in cognitive skills because these nations tend to have an age pyramid characteristic of demographic transition and an educational pyramid with a significant contingent of the adult population having a low educational level (less than nine years of formal education).

In the following discussion, we will separately address the effects of age and educational level on the performance of normal subjects in the inference-making process.

\section{Effect of age on comprehension of textual inference test}

With regard to comprehension of texts with inferences, the main difficulty encountered by elderly compared to younger individuals appears to be related to the interface of this skill with other cognitive functions. The decline in the ability to understand texts and make inferences with age is attributed predominantly to an impairment in working memory ${ }^{(18,19)}$, and the more complex the inference the greater the demands placed on working memory ${ }^{(20)}$. Working memory is related to the comprehension of inferences because individuals must retrieve, maintain, and manipulate information related to the text.

Another possible explanation for the disparity in performance of elderly in the skill of understanding textual inferences can be found in attentional skills. According to this theory, difficulties experienced by elderly in performing two tasks simultaneously or tasks that place greater demands (such as making inferences) can be attributed to decline in the attentional system ${ }^{(21)}$.

Decline in the ability to interpret textual inferences with age may also be justified by a failure to inhibit information that is irrelevant for comprehension, perhaps as a result of impaired executive functions ${ }^{(22,23)}$.

However, other authors advocate the notion that agerelated differences in reading comprehension may be the result of decline in a multiple processes as opposed to one specific process, such as age-associated slowing in various processes ${ }^{(24)}$ and difficulties retrieving knowledge held in long-term memory and integrating this with new knowledge in order to draw inferences ${ }^{(25)}$.

In the present study, poorer performance observed by the elderly on the distractor inferences corroborates the possibility of impaired executive and attentional functions in this 
population, i.e., of problems focusing attention on relevant information while ignoring information that is unnecessary or distracting for comprehension.

This result is corroborated by the findings of McGinnis ${ }^{(22)}$, who stated that differences understanding texts with inference in aging occur because of failures in the inhibition of irrelevant information.

In fact, according to the author of the test used in this study, problems recognizing distractor inferences expose susceptibility of the participants in allowing themselves to follow an interpretative approach and adhere to an incoherent explanation. This reveals mental inflexibility to change the initial reasoning in such questions, which carries a higher degree of uncertainty ${ }^{(17)}$, a limitation which may be related to executive functions.

Hamm and Hasher ${ }^{(26)}$ showed that older individuals exhibited greater activation of alternative interpretations than younger individuals in comprehension of textual inferences and Connelly et al. ${ }^{(27)}$ showed that elderly have greater difficulty in understanding texts containing irrelevant information, particularly when unpredictable. McGinnis ${ }^{(22)}$ concluded that old-old adults are more susceptible to distraction during reading, committing a higher number of comprehension errors compared to younger individuals, having a tendency to select distractor items as response to questions.

\section{Effect of education on comprehension of textual inferences}

In terms of educational level, our results showed that individuals with higher educational level had better performance than individuals with lower educational level on total score of the inference test and across all question types.

The education variable has been reported as an important factor in neuropsychological processing, particularly in countries with heterogeneity in schooling levels, as is the case in Brazil ${ }^{(8,10)}$. According to Ardila ${ }^{(6)}$, the number of years of schooling influenced performance on tasks assessing memory, attention, language and executive functions. Ferreira and Dias ${ }^{(28)}$ reported that inferential processing depends on both the integrity and functioning of these skills, all of which can be acquired and enhanced through the process of formal education.

Concerning the different categories of questions in the present test, the poorer performance seen by individuals with less schooling on explicit questions suggests a primary deficit in reading comprehension (mediated by linguistic complexity, vocabulary, mastery of grammar rules and demands on working memory) and reduced capacity to decode literal concepts, given that explicit inferences do not require inferential reasoning per se.

The difficulty exhibited by individuals with less schooling on logic inferences points to deficit in deduction ability and logical reasoning. Handling logical inferences requires formal reasoning, mental operation strategies for solving logic problems and more complex cognitive operations ${ }^{(17)}$.

The poor performance on distractor questions shown by the individuals with lower educational level suggests mental inflexibility to change reasoning and adherence to an incoherent explanation to answer questions, abilities linked to executive functions, and a phenomenon also observed in the older individuals. Generally, this behavior was evident throughout the application of the test, whereby individuals chose the most predictable, albeit error-inducing, answers, without realizing that the correct information was not present in the text.

This difficulty regarding pragmatic inferences suggests ineffective management of contextualization and rules of pertinence and coherence ${ }^{(17)}$. The superior performance of the most educated group reflects from the importance of world knowledge to interpreting this type of inference. It is presumed that individuals with greater exposure to formal learning activities have increased contact with situations that call for pragmatic solutions, have had greater opportunity to experience a broader variety of sociocultural settings as well as social situations involving different relationships, and consequently have more honed world knowledge and greater resources for drawing inferences.

Marcuschi ${ }^{(29)}$ noted that individuals with low levels of schooling tended to base inferential activity on their personal experience and not on shared knowledge, leading to comprehension problems. Studies on the process of understanding a text and inferential processing have revealed that the type of inference employed by different readers for the same text can vary according to individual sociocultural background ${ }^{(5,30)}$, where knowledge on the subject can influence the automaticity of drawing inferences, since readers with a higher proficiency on the topic can dedicate greater attention to the details of the stimulus $^{(30)}$

On the "others" questions, performance of the groups followed the same pattern as for logical and pragmatic inferences, since "others" questions essentially constitute a combination of these skills. Thus, participants with a low level of schooling had worse performance due to difficulties with formal reasoning and obeying the rules of contextualization as well as limited world knowledge.

\section{CONCLUSION}

A mild influence of age on inference-making from reading was found in this study, regardless of educational level. The elderly group had worse performance than adults in total score on the test and in the distractor questions, possibly as a result of impaired attentional and executive (inhibitory) functions.

In addition, a strong effect of education on inference-making was noted, where highly educated individuals performed better in total test scores and across all categories of questions. This was expected, since educational level is positively correlated with the ability to perform high-demanding cognitive tasks. This difference may also be partly explained by the well known interaction between number of years of study and performance involving various linguistic-cognitive tasks such as episodic memory, attention, reading, vocabulary and executive functions.

The disadvantage presented by low educated individuals in high demanding tasks poses a challenging regarding the discrimination between socio-educational disadvantage and 
disease-related impairment, especially in cases of neurodegenerative diseases affecting cognition (such as Alzheimer's disease).These diagnostic challenges are particularly heightened in developing countries such as Brazil, due to the heterogeneity of formal educational achievements in the general population.

\section{ACKNOWLEDGMENTS}

We thank Veronique Agnes Guernet Steiner and Caroline Fretin de Freitas for their assistance with the translation and back-translation processes of the Implicit Information Management test. We also thank Annick Duchene May Carle for permission to translate and apply the test in the subjects of this study.

*MLS and VUR were responsible for data gathering and tabulation; LLM collaborated with data gathering and tabulation and supervised data gathering; MR observed data gathering and collaborated with data analysis; $M L S, L L M$ and MR were responsible for project and design of the study besides general orientation of execution and elaboration of the manuscript.

\section{REFERENCES}

1. Westby C. 21st century literacy for a diverse world. Folia Phoniatr Logop. 2004;56(4):254-71.

2. Kendeou P, Bohn-Gettler C, White M, van den Broek P. Children's inference generation across different media. J Res Read. 2008; 31(3):259-72.

3. Guitierrez-Calvo M. Inferencias en la comprensión del lenguaje. In: Veja M, Cuetos MF. Psicolinguistica del español. Madrid: Trotta; 1999. p. 231-70.

4. Fonseca RP, Parente MAMP. Inferências e compreensão de metáforas no envelhecimento. In: Parente MAM. Cognição e envelhecimento. São Paulo: Artmed; 2006. p. 169-80.

5. McNamara DS, de Vega M, O'Reilly T. Comprehension skill, inference making and the role of knowledge. In: Schmalhofer F, Perfetti CA. Higher level language process in the brain: Inference and comprehension processes. Mahwah: Erbaum; 2007. p. 233-54.

6. Ardila A. Cultural values underlying psychometric cognitive testing. Neuropsychol Rev. 2005;15(4):185-95.

7. Ostrosky-Solís F, Gómez-Pérez ME, Matute E, Rosselli M, Ardila A, Pineda D. NEUROPSI Attention and memory: a neuropsychological test battery in Spanish with norms by age and educational level. Appl Neuropsychol. 2007;14(3):156-70.

8. Radanovic M, Mansur LL, Scaff M. Normative data for the Brazilian population in the Boston Diagnostic Aphasia Examination: influence of schooling. Braz J Med Biol Res. 2004;37(11):1731-38.

9. Ska B, Joanette Y. Normal aging and cognition. Med Sci. 2006;22(3):284-7.
10. Parente MAMP, Scherer LC, Zimmermann N, Fonseca RP. Evidencia del rol de la escolaridad en la organización cerebral. Rev Neuropsicol Latinoamer. 2009;1(1):72-80.

11. Smith GE, Ivnik RJ. Normative neuropsychology. In: Petersen RC. Mild Cognitive Impairment. New York: Oxford; 2003. p. 63-8.

12. Brucki SMD, Nitrini R, Caramelli P, Bertolucci PHF, Okamoto IH. Sugestões para o uso do mini-exame do estado mental no Brasil. Arq Neuropsiquiatr. 2003;61(3B):777-81.

13. Brucki SMD, Malheiros SMF, Okamoto IH, Bertolucci PHF. Dados normativos para o teste de fluência verbal categoria animais em nosso meio. Arq Neuropsiquiatr. 1997;55(1):56-61.

14. Hamilton M. A rating scale for depression. J Neurol Neurosurg Psychiatry. 1960;23(1):56-62.

15. Xavier F, Ferraz MPT, Gil O, Moriguchi FE. Queixa subjetiva de perda de memória no idoso: uma comparação da percepção dos sujeitos com a percepção dos familiares em estudo na comunidade. Rev Bras Neurol. 1999;35(5):137-41.

16. Goodglass H, Kaplan E. The assessment of aphasia and related disorders. Philadelphia, EUA: Lea \& Febiger; 1983.

17. Duchene May-Carle A. La Gestion de 1’Implicite. Isbergues, France: Ortho Edition; 2000.

18. Calvo MG. Working memory and inferences: evidence from eye fixations while reading. Memory. 2001;9(4):365-81.

19. Borella E, Ghisletta P, de Ribaupierre A. Age differences in text processing: the role of working memory, inhibition, and processing speed. J Gerontol B Psychol Sci Soc Sci. 2011;66(3):311-20.

20. Virtue $S$, Parrish T, Beeman MJ. Inferences during story comprehension: cortical recruitment affected by predictability of events and working memory capacity. J Cogn Neurosci. 2008;20(12):1-11.

21. Milham MP, Erickson KI, Banich MT, Kramer AF, Webb A, Wszalek T, et al. Attentional control in the aging brain: insights from an FMRI study of the Stroop task. Brain Cogn. 2002;49(3):277-96.

22. McGinnis D. Susceptibility to distraction during reading in young, young-old and old-old adults. Exp Aging Res. 2012;38(4):370-93.

23. Kristensen CH. Funções executivas e envelhecimento. In: Parente MAM. Cognição e envelhecimento. Porto Alegre: Artmed; 2006; p. 97-112.

24. Salthouse TA. The processing speed theory of cognitive aging. Psychol Rev. 1996;103(3):403-28.

25. Hannon B, Daneman M. Age-related changes in reading comprehension: an individual-differences perspective. Exp Aging Res. 2009;35(4):432-56

26. Hamm VP, Hasher L. Age and the availability of inferences. Psychol Aging. 1992; 7(1):56-64.

27. Connelly SL, Hasher L, Zacks RT. Age and reading: The impact of distraction. Psychol Aging. 1999;6(4):533-41.

28. Ferreira APA, Dias MGBB. Reading, sense production and the inferencial process. Psicol Estud. 2004;9(3):439-48. [Portuguese].

29. Marcuschi LA. O processo inferencial na compreensão de textos. Relatório Final apresentado ao CNPq. Programa de Pós-graduação em Letras e Linguística. Recife: Universidade Federal de Pernambuco; 1989.

30. McNamara DS. Reading both high-coherence and low coherence texts: Effects of text sequence and prior knowledge. Can J Exp Psychol. 2001;55(1):51-62. 
Appendix 1. Types of questions from the Implicit Information Management test

\begin{tabular}{|c|c|c|}
\hline Question type & Explanation & Example \\
\hline $\begin{array}{l}\text { Explicit } \\
\text { (11 questions) }\end{array}$ & $\begin{array}{l}\text { Require literal translation of the statement, but no inferential } \\
\text { reasoning per se. }\end{array}$ & $\begin{array}{l}\text { Nadia called Lucas and told him: "My goodness, have you seen the time?", } \\
\text { and Lucas answered: "Yes, I know, but I can't find my car keys." } \\
\text { Has Lucas lost the keys to his car? }\end{array}$ \\
\hline $\begin{array}{l}\text { Logical } \\
\text { (12 questions) }\end{array}$ & $\begin{array}{l}\text { Engage the use of formal reasoning and processes of } \\
\text { deduction. }\end{array}$ & $\begin{array}{l}\text { My neighbor's cat never meows, except when it hasn't eaten for a long } \\
\text { time. Today, I heard the cat meowing all morning. } \\
\text { Did my neighbor feed her cat this morning? }\end{array}$ \\
\hline $\begin{array}{l}\text { Distractor } \\
\text { (13 questions) }\end{array}$ & $\begin{array}{l}\text { Questions to which subject should answer with "Cannot } \\
\text { answer", because the information requested does not exist } \\
\text { in the test, explicitly or implicitly. Designed to check whether } \\
\text { subject is able to deviate from an interpretive approach and } \\
\text { provide an explanation not defined spontaneously. }\end{array}$ & $\begin{array}{l}\text { Rose says to Suzanne: "Stop eating or you'll put on weight!" and } \\
\text { Suzanne replies: "So what, men like it." } \\
\text { Is Rose married? }\end{array}$ \\
\hline $\begin{array}{l}\text { Pragmatic } \\
\text { (18 questions) }\end{array}$ & $\begin{array}{l}\text { Require knowledge of usual scripts, logical and coherent } \\
\text { action plans and conformance to discursive rules. }\end{array}$ & $\begin{array}{l}\text { After the weather report, Brigitte said to herself: "I mustn't forget my } \\
\text { umbrella tomorrow". } \\
\text { Does Brigitte like getting wet? }\end{array}$ \\
\hline $\begin{array}{l}\text { Other } \\
\text { (6 questions) }\end{array}$ & $\begin{array}{l}\text { Require handling of logic operations together with pertinent } \\
\text { contextualization (combination of logic and pragmatic } \\
\text { competencies). }\end{array}$ & $\begin{array}{l}\text { Peter says:"It costs a lot of money to go to Canada; I can't go there right now.' } \\
\text { Does Peter have a lot of money right now? }\end{array}$ \\
\hline
\end{tabular}

